\title{
The Clinic of the Psychosomatic Patient: Searching for the Meaning of Symptoms
}

\section{Lazslo Antonio Avila*}

Medical College of Sao Jose do Rio Preto, Sao Jose do Rio Preto, Sao Paulo, Brazil

"Corresponding author: Lazslo Antonio Avila Ph.D., Medical College of Sao Jose do Rio Preto, Sao Jose do Rio Preto, Sao Paulo, Brazil, Tel: 55 17 32324905 ; E-mail: lazslo@terra.com.br

Received: Mar 13, 2014, Accepted: May 28, 2014, Published: Jun 4, 2014

Copyright: (C) 2014 Ávila LA. This is an open-access article distributed under the terms of the Creative Commons Attribution License, which permits unrestricted use, distribution, and reproduction in any medium, provided the original author and source are credited.

\begin{abstract}
This paper focuses on some problems emerging from the doctor-patient relationship, when subjectivity is identified and considered. We discuss the passivity and alienation of the patient manifest in the current medical approach to sickness.

Then, we stress the role of psychotherapy in allowing apprehension of the meanings that all diseases have, when lived as personal illnesses. We present a case report of a 'difficult' patient treated by psychodynamic psychotherapy.
\end{abstract}

Keywords: Psychosomatic medicine; Psychoanalysis; Medical psychology

\section{Introduction}

The apprehension of the meaning of the symptoms of the patient can be derived from the careful analysis of the links between the onset of the symptomatology and relevant aspects of the life history of the individual. The biography, in broad and deep sense; comprising of the emotional, the intellectual and the physical history, shows that an illness is never a purely "objective" fact, affecting the individual from outside, meaning that it is not just an accident.

A disease is lived as an illness, full of experiences. It always represents a lot of consequences and meanings for the man, or woman, who is affected by it. It is only in psychiatric settings that the person can ignore a disease, but this is already part of the mental illness. A physical, or even a functional disease, affects the life, and eventually can transform it. Therefore, the ill person is normally deeply concerned with all aspects of what he/she suffers. The individual is interested in the origin, the course, the treatment, the side-effects, the consequences on the quality of life, and most of all, with the cure of his/her affliction. However, normally, doctors are trained in a way to keep the knowledge of the disease out of the reach of the patient, and so the physician remains the only person who can discern what is best for the patient.

The development of the patient-doctor relationship, principally over the last three centuries, has transferred the control of the disease from the patient to the doctor. Now, more than ever, the patient has become really passive, a subjected entity, open to the guidance of another; the doctor. Therefore, the patient has become a subject similar to an object. This was implicit in the adoption of the word "patient", whose etymology shows interesting connections: the Greek word paschein means "passion" and "passivity". The passion that suffers the ill person is both, the passionality of the feelings, as in the necessity of protection, care, and interest, and the passion in the sense of the Christ's passion, that is, pain, worry, despair. On the other hand, paschein is the passivity, which is required in order to follow the instructions of another, the wise one, who knows what the disease "is", how to treat it, and what are the attitudes convenient for both; doctor and "patient".

Everyone knows that this is unconfirmed by reality, and in real life, the patient denies being absolutely confident in all orientation of his/her doctors, trying not to give up his independence and selfdirection. In general, this is shown in the management of the treatment. Many patients manifest their resistance, hiding their medicines under their pillows, changing by themselves the quantities of medicines and schedules of ingestion, deciding for self-medication, looking for many different types of alternative or complementary medicine, changing doctors, consulting relatives, neighbors, etc. In the doctor-patient relationship, there is frequently an exasperation of both, the doctor striving to keep his/her authority, and the patient insisting to be acknowledged as an autonomous individual. A great deal of the efficacy of the treatment depends on this conflict.

All of this is well known in psychoanalysis and in medical psychology, and it is studied under the general conceptions of the transference, the resistance, and the significance of the ego autonomy for the development of the personality. The problem is: the psychodynamic approach to the diseases is considered to be very specific, distant from the practice of usual medicine, and its phenomena are considered proper to the neurotic and psychotic personalities. However, the unconscious is universal, and its manifestations are ubiquitous. Doctors and patients live their reciprocal acts and feelings, and can perceive only a small part of the totality of emotions, thoughts and meanings that may occur during their interactions. An important exception to this occurs when doctors perceive that information is essential for the development of the treatment and adopts measures such as psychoeducation. It has been largely used all around the world, with excellent results.

To further discuss lets divide the problem in three inter-linked aspects: 1) the meaning of the disease for the doctor; 2) the meaning of the disease for the patient; 3 ) the meaning of the disease for the personality and the life of the individual. This does not implies in all multiple aspects of the complexity involved in a single disease, but 
only a small part of it, since there are other dimensions far from the range of this analysis.

As to the first point, it is important to understand that Medicine has defined diseases as pathological entities, universally defined, with a set of fixed characteristics that transcend history and society, because they are independent of where or when they occur. The epistemological orientation of Medicine towards Biochemistry and Biophysics make doctors perceive different diseases as minimal variations of the same pattern of traits, which, by themselves, are "objective", that is, they are conceived as real and a-historical, thus non-contingent. Departing from this definition and assumptions, doctors are not inclined to accept subjective conceptions of diseases by the patients or their relatives. Although they can accept that the ill person can have some particularities, for them, the disease is independent of its conception, and therefore it should be approached from its biological identity, instead of by the descriptions of the sick. There is a current suspicion on the opinion of the patient in the matters of what the disease is, what its signs and symptoms are and mean, and especially in how to manage it, until recovery.

But, and here enters our second point, the patient refuses to be only a "carrier" of the disease. The patient feels a disease as a personal matter, very important in whatever form. It is true that the most important aim is to be free of the disease, and that the sick is inclined to listen, respect, and follow the doctor's orientation. Nevertheless, the patient remains interested to know about what causes diseases, how to prevent them, how to deal with their symptoms, how to face the consequences of being ill, and in all impacts of disease on his/her life. Thus, the person refuses to be only an organism, and demands insistently to be viewed and treated as a whole person. Medicine, ideally, wants to deal with the biological organism of the ill, and with biological aspects of its transformation during and after the pathological process. Nevertheless, ill people want, overall, to recover, and to maintain their individuality. At the core of this problem is the question of liberty. Men and women can accept to follow orientation, and even orders, but they must agree with this situation. Every deprivation of this liberty will be resented, even if the individual requires being part of a situation where he needs to accept submission.

In general, pain, impairment of functions and movements, anguish and other feelings make a man/woman become a patient. As long as he/she looks for a doctor, he/she is instantly converted into a patient. In addition, with the increase in gravity of the problem, or intensity of the symptoms, a person can give up more completely of his/her own judgement in the situation. Nevertheless, this is temporary. Even after a profound catastrophe, like a heart infarction, a man/woman wants to direct his/her own life, although guided by technical information. A diet can be followed, exercises can be prescribed and executed, medication can be rigorously accepted, a surgery under complete analgesia can be performed, but even so the individual will still want to re-establish his autonomy, as soon as possible. Instruction can be accepted, but the freedom of people will appear in their necessity to take part in the decisions concerning their health.

Thus, for the patient, disease is a personal matter. As far as he can understand what happened to him, in illness as well as in cure, he will want to achieve control and comprehension of the facts. But this is not the same aim of the doctor, and in the relationship with him, this can take the form of open conflict, and several different faces of seduction, induction, malingering, authoritarianism, bad-faith, avoidance, and other distorted forms. Events are worse when unconscious. The awareness of the situation's delicacy can help the doctor-patient relationship to become one of co-operation, understanding, and progress in diagnosis and treatment.

Finally, the third and most comprehensive point; meaning of disease in terms of the personality. Here we must consider several dimensions, which can also be grouped in three categories: a) The disease as an illness, which is, taken subjectively; b) the disease as a transforming experience; $c$ ) the relation doctor-patient, as the ground where communication, meaning and intervention occur. More correctly, doctor here should be considered clinician, in order to include different therapists, like the psychotherapist.

In item (a) we must consider two facts: first, the scientific evidence that shows that diseases are inevitably extended and modified by a large number of personal factors ranging from environmental circumstances, to the most intimate causations, as we can see in the pain experience. It is well known that pain cannot be objectively measured and quantified, and that no technical apparatus can detect or photograph it. Pain is simultaneously a very concrete, but ineffable experience. Studies like the one conducted by Birket-Smith, [1], concluded that: "the experience of pain is related not only to tissue damage and physical illness, but to mental phenomena including depression, anxiety and somatization". In the effort to differentiate chronic pain, Kautzsch and Kopf insisted in the complexity of the interaction between pain and personality factors, defending that the interdisciplinary work should involve medical and nursing staff, besides psychologists [2]. Many other studies exist, proving that different individuals show different thresholds in their immunological, endocrinological, or neuro-muscular systems, to react to different aggressions by viruses, bacteria, pollution, poisoning, etc., associated with personality factors and psychopathology [3]. There are also several studies giving strong evidence about connections between pain experience with life history and emotional events previous to the pain's onset [4].

In the area of studies known as "Environmental Medicine" [5], there are many well-described syndromes that are poorly understood, and show how many possibilities exist to manifest a state of disease, with all its signs and consequences. Nonetheless, very little can be done to really achieve knowledge and control; either of the pathological process or of the causations. Among those diseases, we found: MCS or Multiple Chemical Sensitivities, IES or Idiopathic Environmental Intolerances, SBS or Sick Building Syndrome, CFS or Chronic Fatigue Syndrome, CS or Candida Syndrome and BS or Burnout Syndrome. Under the façade of so many syndromes, it is obvious the presence of the exhaustively described concept of "stress", popularized by Hans Selye, and one of the most studied syndromes over the last fifty years. Fatigue, and its new fashioned cluster, or CFS, in particular, has recently received a lot of attention [6].

All these conditions are the focus of great concern, since doctors and the public started to examine the vague domain of the so-called "medically unexplained" symptoms. In England, in a Conference held in 1992, the Royal College of Physicians, in association with the Royal College of Psychiatrists, took the position of firmly recommending studies and training both of general practitioners and psychiatrists, in order to face these symptoms. The target is the broad and rich symptomatology, which cannot be fully explained by any organic medical disease or biological causation, but which causes severe disability, high costs, and a great amount of suffering for patients. Among the main symptoms covered by this label, the most frequent are: chest pain of non-cardiac origin, abdominal pain, back pain, irritable bowel syndrome, breathlessness, dizziness, fatigue and 
headache. In a book derived from this meeting, the authors argue that non-organic symptoms are very common, pose a major clinical problem, and are, at the present moment, generally poorly managed by doctors [7]. The participants considered that physical, psychological and social factors interact in the production of the "medically unexplained" symptoms and that "psychiatric disorders such as anxiety and depression are common, but wider psychological factors, relating to an individual's knowledge and beliefs, are also important in our understanding of these disorders" [8].

Studies on the subject, like the one conducted by Feder et al. [9], showed that patients with multiple "medically unexplained" symptoms were greatly functionally impaired and had over twice the rate of psychiatric disorders. It is frequently pointed out, by both researchers and doctors, that these problems should be treated in primary care institutions, but effective management strategies are not welldeveloped [10]. What is sure is that these symptoms are frequently expressions of somatization, or somatoforme disorders. As expressed by Birket-Smith: "somatoforme patients are often given inappropriate diagnoses, treated for non-existent depressive disorders, and exposed to multiple, superfluous investigations" [11].

Nevertheless, we will consider this problem in another paper. Now, let us resume our argument. Besides scientific studies, there is another important point in relation to item (a) "The disease as an illness". And this is the opinion of the patient. By opinion, here, we mean his representations, his will, his cognitions and feelings, his ideology, etc. The illness is a personal matter, of uttermost importance. The patient's viewpoint interferes in what "is" the disease. This is because the disease, when lived by a person, becomes "his" or "hers" illness. The patient's perspective in relation the origin, causes, development and/or resolution of his/her symptoms may have no scientific basis. Nevertheless, it has rights the right to be taken into account. A pain may, or may not, be considered the most tragic fact. A simple diet can be considered a total punishment. A medication can be seen as a "demoniac" danger (as, by the fact, can be seen in the etymology of the word "drug", whose Persian root means "demon"). So, the subjectivity of the patient is always awakening in the process of illness, and cannot be erased from his/her relationship with the doctor.

In addition, this conducts us to the second point: the disease is an experience, often a very disturbing experience, with a potential of affecting the whole life of an individual. The disease in his/her heart hits the man or woman who suffers, and this is not only metaphoric. A disease can move a person, and severe disease can move more extensively. This is why the ill person need much more than simply be attended with the most modern, precise and sophisticated techniques. The patient needs to be understood.

Then, the relationship of the person with the disease has to be mediated by another person, the clinician. The physician will have to be prone to interact not only with the "fact" of the disease, but with the person, the suffering and demanding person. In this moment, frequently, the psychotherapist is needed. The medical training, in general, does not provide doctors with the relevant arsenal to deal with the emotional impact of the disease upon the patient. It is necessary a very good background to face the meanings of the disease for the sick.

The basic meanings of disease are: death, limitation, fear, anguish, impotence. The emotional distress is not a boring "side-effect"; it is a real and inevitable part of the problem. Even a light disease is a danger, and can represent a fearful experience. However, experiences are not shown in X-rays or tomographies. Experiences must be shared. The apparatus needed for that is another subject, that is, a human interaction, a companion in (to) the whole experience.

\section{Case Report}

The patient is 60 years old, and he has laid on bed the last 22 years. His primary diagnosis is osteoarthritis, but his clinical situation is much worse, since his position brought several complications: water on his lungs, malfunctioning of many organs, like kidneys, vesicule, bladder, etc., mio-asthenia and a severe drop down in his immunity.

I came to attend him at the request of his older daughter, a medical doctor. She told me that he was an old chronic patient, well-known by many health services and professionals. She had been taking care of him for a long time. She did not expect great changes in his clinical state, but asked for my help, fearing his reaction to a great change in her personal life: she was considering moving from home, to a distant town.

Besides several different specialties, this man had had five different psychiatrists treating him in the last 20 years. All of them failed in keeping the patient. This man manipulated medicines and doctors and interrupted all the therapeutic attempts.

Now, she was convinced that a dead-end had come, and she decided to leave home, letting her father and his illness. This opened his resistances and he agreed to have psychotherapeutic sessions. Mixing feelings and severe arousals turned his treatment a very intense experience. First, he brought a vivid description of the familiar life and about his motivation to keep them tightly together. Then, he started analyzing himself, and the links between his biography and his physical symptoms. Finally, he faced the origin and the meaning of his disease.

His illness started with a fall from scaffolding. He offended his spinal column, staying in a hospital for two weeks, after which his doctors released him, prescribing physiotherapy. However, the patient complained of violent pain, and was re-admitted to the hospital. New examinations were performed, with no results. The man showed severe disability, and the family looked for other medical services. A pilgrimage started. Many doctors and clinics were visited orthopedists, rheumatologists, neurologists, pain specialists were consulted, and the patient did not improve, nor had any relieve in his main symptom: pain.

He got medical licenses, and after some years of fruitless investigation, the insurance system decided for his permanent disability and he retired. After that, he lived in his house, and all subsequent treatments were made at his home.

He got the most diverse diagnoses, but the etiology of his pain could never be established. Although some psychiatrists suspected of a conversive disorder, his suffering and motor difficulties convinced the family that this man was physically ill, and accepted the situation.

I entered his room, at his house, and found a reproduction of a hospital's room. A metallic wardrobe full of medicines, a rack with shelves plenty of exams, $\mathrm{X}$ rays, tomographies and medical apparatuses, and a sophisticated hospital bed. It was like a kingdom, and soon I realized that from the middle of this kingdom, he ruled with iron hand.

His family's composition: he, his wife and four daughters. Every one of them lived quite closely to him: he never permitted to any of them to sleep out of home, to travel, to have acquaintances, to date. All of 
them were single, although the older was over the 30's, and the youngest was 22 years old. Only two of them had jobs, the doctor and the third, who was a secretary in an office nearby. The family had few friends, most of them relatives of the father's.

The emotional pattern of the familiar group was of tight linkages, warranted by compulsive control of the member's behavior, done by the father. This man believed that the happiness of all the family was dependent on their union, and his idea of this union was the physical presence, the maintenance of the familiar rituals, and the continuity of stereotipized habits. In addition, in this situation, his sickness played a very important role.

Being ill this man had a weapon and a blackmail instrument: any contestation of his authority, he would react with the worsening of some of his symptoms. If a daughter managed to get a boyfriend, her father would make her feel guilty, because he would need her for his care.

At the beginning, this man accepted the therapeutic aid, because the situation seemed to crash, if a daughter could flee from home, the door would be opened, allowing others to follow the first one. He would have to face his worst nightmare: solitude. Even his wife, he feared, would leave him, to follow some of her daughters. Alone and sick, he would die. He was considering suicide. He could not bear the separation.

The treatment helped both the patient and his family, because it broke with the established balance of his sickness. Understanding the significance of his paralysis and its consequences in the behavior of his relatives allowed that all members of the family could discuss the alternatives that permit the emergence of another pattern of relationships. Proximity and affectivity could not be the result of blackmailing and secondary benefits. Love is not negotiable, and cure sometimes mean the acknowledgement of the necessity of transformation, personal and environmental.

\section{Discussion}

What can be derived from the particularities of this case report, searching amidst the richness of any individual history? We shall look for a pattern of construction. We believe, based on the heritage of the first psychosomatic pioneers, that a disease is a lived illness: a personal experience. Far from denying the biological basis of any disease, we think that the sick cannot be cut off of him when he goes to the doctor. The soul cannot wait hanging in the closet, while the only subject present in the scene consults the body: the physician.

What we can find in this report is the cry of the subject: not his pain of physical suffering, but the pain of being excluded in the partnership of the doctor-patient encounter. A subject demands consideration, and the main aspect of this consideration is the inner acknowledgement that the subject guides himself and praises this capacity as one of his/her most precious personality components.
The case comprises many difficult experiences. What can do a doctor when faced with such complexities? At minimum, he/she must be aware to the meanings lived by the patients when and while they are living their diseases. How life and disease can interpenetrate each another, in a delicate mosaic, in a solid tissue of new realities? Symptoms and feelings, pain and meanings, disability and family consequences, all of this is brought through, and the subject is the author of a complex and unknown situation. A virus or an accident is external events. However, to get ill, and especially when the illness becomes a very important part of everyday life, is conjointly decided by nature and by will. The complication of this is the presence of unconscious forces.

This is the reason why a psychoanalytical inquiry may be as necessary as all the biological examinations that the doctors are obliged to perform. The psychoanalyst or even a well-trained general physician should, as Hypocrites did, investigate the links between life and pathology, personal history and onset of symptomatology, chronicity and desires, fears or expectations, and aggravations or ameliorations of symptoms. In a word: sickness and subjectivity.

\section{References}

1. Birket-Smith M (2001) Somatization and chronic pain. Acta Anaesthesiol Scan 45: 114-120

2. Kautzsch K, Kopf A (2001) Differential diagnosis of pain experience. Chronic pain and depression. Fortschr Med Orig 118: 153-156.

3. Dersh J, Polatin PB, Gatchel RJ (2001) Chronic pain and psychopathology: research findings and theoretical considerations, Psychosom Med 64: 773-86.

4. Baccini F, Pallotta N, Calabrese E, Pezzotti P, Carazziari E (2003) Prevalence of sexual and physical abuse and its relationship with wymptom manifestations in patients with chronic organic and functional gastrointestinal disorders Dig Liver Dis 35: 256-61.

5. Wiesmüller GA, Ebel H, Hornberg C (2001) Syndromes in environmental medicine: variants of somatoform disorders]. Fortschr Neurol Psychiatr 69: 175-188.

6. Youssefi M, Linkowski P (2011) Le syndrome de fatigue cronique: aspects psiquiatriquesVer Med Brux 23: 299-304.

7. Creed F, Mayou R, Hopkins A (1995) Medical Symptoms not Explained by Organic Disease. London: The Royal College of Psychiatrists and the Royal College of Physicians of London.

8. Creed; Mayou \& Hopkins - Op. cit., p. ix.

9. Feder A, Olfson M, Gameroff M, Fuentes M, Shea S, et al. (2001) Medically unexplained symptoms in an urban general medicine practice. Psychosomatics 42: 261-268.

10. Reid S, Whooley D, Crayford T, Hotopf M (2001) Medically unexplained symptoms-GPs' attitudes towards their cause and management. Fam Pract 18: 519-523.

11. Birket-Smith, M - Op. cit., p. 114. 